Research Article

\title{
Ultrasensitive Detection of 2,4-Dinitrophenol Using Nanowire Biosensor
}

\author{
Yuri D. Ivanov, ${ }^{1}$ Kristina A. Malsagova ${ }^{D},{ }^{1}$ Tatyana O. Pleshakova ${ }^{1},{ }^{1}$ Rafael A. Galiullin, ${ }^{1}$ \\ Andrey F. Kozlov, ${ }^{1}$ Ivan D. Shumov, ${ }^{1}$ Irina A. Ivanova, ${ }^{1}$ Alexander I. Archakov, ${ }^{1}$ \\ Vladimir P. Popov, ${ }^{2}$ Alexander V. Latyshev, ${ }^{2}$ Konstantin V. Rudenko, ${ }^{3}$ \\ and Alexander V. Glukhov ${ }^{4}$ \\ ${ }^{1}$ Institute of Biomedical Chemistry, Ul. Pogodinskaya 10, Build. 8, Moscow 119121, Russia \\ ${ }^{2}$ Rzhanov Institute of Semiconductor Physics, Siberian Branch, Russian Academy of Sciences, Pr. Akad. Lavrent'eva 13, \\ Novosibirsk 630090, Russia \\ ${ }^{3}$ Physical Technological Institute, Russian Academy of Sciences, Nakhimovskii Pr. 36/1, Moscow 117218, Russia \\ ${ }^{4}$ Novosibirsk Semiconductor Device Plant and Design Bureau, Ul. Dachnaya 60, Novosibirsk 630082, Russia
}

Correspondence should be addressed to Kristina A. Malsagova; krisiki86@mail.ru

Received 6 March 2018; Revised 19 July 2018; Accepted 12 August 2018; Published 17 October 2018

Academic Editor: Zhonggang Liu

Copyright $\odot 2018$ Yuri D. Ivanov et al. This is an open access article distributed under the Creative Commons Attribution License, which permits unrestricted use, distribution, and reproduction in any medium, provided the original work is properly cited.

The method for the detection of 2,4-dinitrophenol (DNP) in solution is proposed. This method employs the sensors based on silicon nanowire field-effect transistors with protective layers of high- $k$ dielectrics, whose surface is functionalized with an amino silane. Direct highly sensitive detection of DNP has been demonstrated, and the lowest detectable concentration of DNP was determined to be $10^{-14} \mathrm{M}$. Silicon-on-insulator nanowire (SOI-NW) sensors can well be employed for the rapid detection of a wide range of toxic and explosive compounds by selection of sensor surface modification techniques.

\section{Introduction}

2,4-Dinitrophenol (DNP) pertains to nitroaromatic compounds. It represents a crystalline solid, which is slightly soluble in water and readily soluble in boiling water and in organic solvents, such as ethanol and diethyl ether [1]. DNP is widely used in chemical industry [2] as a component of explosives and fungicides, as well as in textile industry as a dye for fabrics [3-6]. Regarding the physiological effect, DNP is reported to cause rapid loss of weight, but unfortunately is associated with an unacceptably high rate of significant adverse effects [7] due to its toxicity (lethal dose low $36 \mathrm{mg} / \mathrm{kg}$ (human) [8]). DNP poisoning can result in death in some cases $[4,7,9,10]$. Clinical symptoms of DNP poisoning include anorexia, nausea, vomiting, headache, dizziness, feeling of suffocation, as well as general weakness, and weight loss $[4,11,12]$. In this respect, modern nanotechnology-based sensor platforms can well be of use in order to provide rapid monitoring of toxic organic compounds in human biomaterial. For instance, Maduraiveeran et al. recently developed a bimetallic nanoparticlebased amperometric sensor for the rapid detection of acetaminophen (a drug for the relief of fever and pain, which sometimes develops a fatal hepatoxicity and nephrotoxicity [13]) in human serum with subnanomolar concentration sensitivity [14].

Moreover, it is to be noted that DNP is highly explosive [15]. This is the reason why the development of highly sensitive, rapid, cheap, and easy-to-use detectors for the revelation of DNP in the environment is crucial. The optimal solution of this problem is the use of silicon nanowire (NW) field-effect transistor sensors. As the size of a nanowire is comparable with that of a biological macromolecule [16], most attention is paid to the use of silicon-on-insulator nanowire (SOI-NW) sensors for the detection of protein and nucleic acid disease markers [17-20]; the possibility of application of these sensors for cancer diagnosis in exhaled air was also shown [21]. With respect to biological 
macromolecules, nanotechnology-based electrochemical methods allow one to attain very low detection limits [22], in contrast to small molecules and ions, when the detection limits are commonly in nanomolar to micromolar range [23].

Nevertheless, silicon NW-based devices are also successfully employed for the detection of small molecules and ions. In this regard, it is worth noting that SOI-NW sensor structures display $\mathrm{pH}$ sensitivity [24]. The silicon NW-based detection of mercury ions at $10^{-7} \mathrm{M}$ concentration was demonstrated by Luo et al. [25]. The studies concerning NW-based gas-phase detection of small-molecule analytes, including inorganic gases and vapors, organic explosives, nerve agents, and volatile organic compounds, are reviewed in the paper by Cao et al. [26]. The liquid-phase detection of aromatic compounds was demonstrated by Talin et al. with examples of nitrobenzene and phenol in cyclohexane [27]; however, in this study, the analyte concentrations $<10^{-3} \mathrm{M}$ were not tested. Engel et al. demonstrated the use of NW sensors for the detection of DNP, 2,4,6-trinitrotoluene and other nitroaromatic chemicals in solution with $5 \times 10^{-13} \mathrm{M}$ concentration sensitivity. These authors also showed that careful selection of surface chemistry of SOI-NW sensor can provide detection specificity [28]. For another nitroaromatic explosive, trinitrotoluene (TNT), even lower detection limit $\left(\sim 10^{-14} \mathrm{M}\right)$ was attained by Lichtenstein et al. [29].

It is to be noted that the NW sensors used by Engel et al. [28] were fabricated by «bottom-up» method; with regard to mass production, this method is insufficiently feasible. In our present study, lower-submicron complementary metaloxide-semiconductor (CMOS)-compatible technology employing subgate dielectrics with high dielectric constant (high- $k$ ) has been used for fabrication of SOI-NW sensors. This technology allows one to fabricate highly sensitive SOINW sensors. In this connection, it is to be noted that deposition of ultrathin dielectric layers onto NW sensor elements significantly improves their chemical stability (which directly influences the sensor performance). This was demonstrated in the study by Peled et al. with the example of deposition of 3 to $10 \mathrm{~nm}$-thick $\mathrm{Al}_{2} \mathrm{O}_{3}$ layers onto silicon $\mathrm{NW}$ sensors [30].

Herein, we have demonstrated that, using such sensors, the lower limit of DNP detection in solution can be shifted down to $3 \times 10^{-14} \mathrm{M}$; this value is an order of magnitude lower than that reported by Engel et al. [28], and comparable with that obtained for TNT by Lichtenstein et al. [29]. In this way, further development of SOI-NW-based sensing, including techniques of chemical modification of SOI-NW sensor surface, will provide selective detection of DNP and other toxic and explosive compounds with high concentration sensitivity.

\section{Materials and Methods}

2.1. Chemicals. 2,4-Dinitrophenol, ethanol $\left(\mathrm{C}_{2} \mathrm{H}_{5} \mathrm{OH}\right.$, $96 \%$, and isopropanol $\left(\mathrm{C}_{3} \mathrm{H}_{7} \mathrm{OH}, 99.999 \%\right)$ were purchased from Reakhim (Russia). 3,3'-dithiobis (sulfosuccinimidyl propionate) (DTSSP cross-linker) was purchased from Pierce (USA). 3-aminopropyltriethoxysilane (APTES) was purchased from Sigma-Aldrich (USA). Deionized water was obtained using the Milli-Q system (Millipore, USA).

2.2. Fabrication of SOI-NW Sensors. SOI-NW sensors with n-type conductivity were fabricated by optical lithography. The initial silicon layer thickness was $45 \mathrm{~nm}$, and buried oxide (BOX) thickness was $200 \mathrm{~nm}$. The SOI-NW sensor elements had the following dimensions: $250 \mathrm{~nm}$ width, $32 \mathrm{~nm}$ thickness, and $14 \mu \mathrm{m}$ length; the number of SOI-NW sensors on the sensor chip crystal was 12 (Figure 1). The surface of SOI-NW sensor chip was entirely coated with a dielectric layer using the FlexAl reactor (Oxford Instruments, UK) by plasmaenhanced atomic layer deposition (PEALD). Prior to dielectric deposition, immediately before PEALD procedure, the surface of SOI-NW sensors was cleaned first in $\mathrm{H}_{2} \mathrm{O}_{2} / \mathrm{NH}_{3}$ solution and then in $\mathrm{NH}_{3}$ plasma at $500 \mathrm{~W}$ power and 50 mTorr working pressure for $2 \mathrm{~min}$. Deposition of $\mathrm{HfO}_{2}$ and $\mathrm{Al}_{2} \mathrm{O}_{3}$ was carried out by cycles in oxygen plasma. An $8 \mathrm{~nm}$ thick $\mathrm{HfO}_{2}$ layer was formed from tetrakis(ethylmethylamino) hafnium(IV) precursor at $270^{\circ} \mathrm{C}$. A $4 \mathrm{~nm}$-thick $\mathrm{Al}_{2} \mathrm{O}_{3}$ layer was formed from trimethylaluminum precursor at $300^{\circ} \mathrm{C}$. After PEALD procedure, SOI-NW sensors were annealed in the forming gas $\left(\mathrm{N}_{2}: \mathrm{H}_{2}=95: 5\right)$ at $425^{\circ} \mathrm{C}$ and 200 mTorr for $30 \mathrm{~min}$. In the SOI-NW sensor system, a $500 \mu \mathrm{L}$ measuring cell was employed, and the SOI-NW sensor chip served as its bottom. The diameter of the sensor area was $\sim 2 \mathrm{~mm}$. The cell was equipped with a stirrer. The stirring rate was $3000 \mathrm{rpm}$.

2.3. Sensor Surface Modification. To remove organic contaminants, the surface of SOI-NW sensor chip was treated with isopropanol and then silanized in 3\% APTES solution during $60 \mathrm{~min}$ at room temperature to provide amino functionality of the surface analogously to the technique described by Shehada et al. [31]. After silanization, the surface of SOI-NW sensor chip was treated with ethanol. The surface of control SOI-NW sensors was additionally modified with DTSSP cross-linker [20, 32]. Figure 2 displays the schematic representation of DNP detection with APTESmodified nanowires.

2.4. Preparation of Solutions. A series of test solutions of DNP with concentrations ranging from $10^{-12} \mathrm{M}$ to $10^{-15} \mathrm{M}$ were prepared from $0.05 \mathrm{M}$ stock solution of DNP in ethanol by serial tenfold dilution. On each dilution stage, the solution was incubated in a shaker for $30 \mathrm{~min}$ at $10^{\circ} \mathrm{C}$. Control experiments were carried out with solutions that did not contain DNP. All liquids used in the experiments were filtered using Vivaspin Turbo 15 centrifuge filters (3000 MWCO; Millipore, USA). The solutions were prepared directly before measurements.

2.5. Electrical Measurements. Electrical measurements were carried out using Keithley 6487 picoammeter (Keithley Instruments Inc., USA). During measurements, the support of SOI structures was used as a control electrode (transistor gate). The dependence of drain-source current on gate voltage $I_{\mathrm{ds}}\left(V_{\mathrm{g}}\right)$ for n-type SOI-NWs was obtained at 


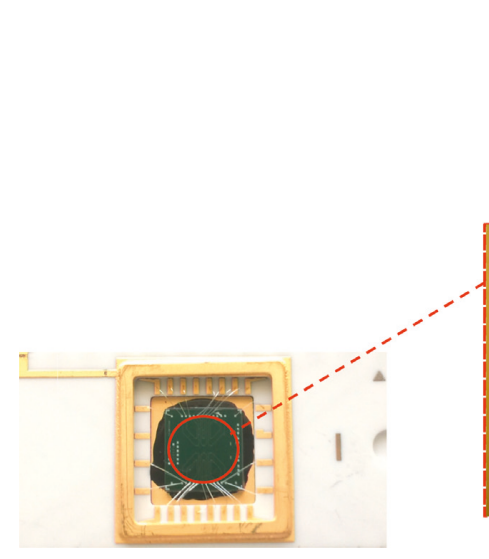

(a)

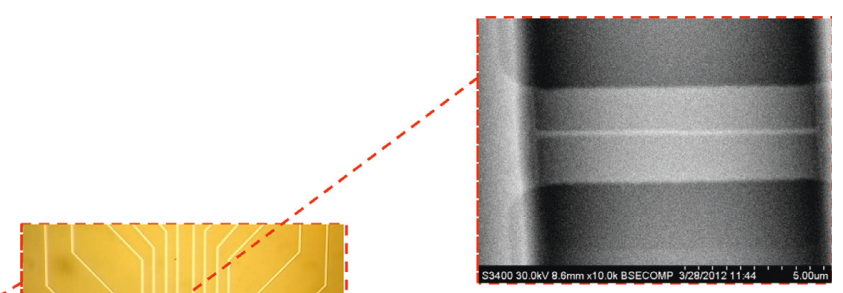

(c)

FIGURE 1: (a) Sensor chip with an array of SOI-NWs, (b) optical image of 12 SOI-NWs arranged in pairs on the chip surface, and (c) electron microscopy image of a single SOI-NW.

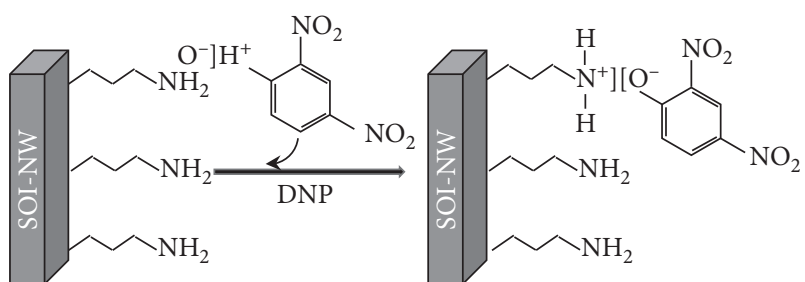

Figure 2: Scheme of DNP detection with APTES-modified nanowires.

$V_{\mathrm{g}}=0 / 70 \mathrm{~V}$ and $V_{\mathrm{ds}}=0.2 \mathrm{~V}$. For the detection of DNP with the SOI-NW sensor, $150 \mu \mathrm{L}$ of test solution of DNP was added into the measuring cell containing $300 \mu \mathrm{L}$ of water. To account for the nonspecific signal, control experiments with use of DNP-free solutions were carried out in the same conditions. Time dependencies of normalized differential drain-source current signal $\Delta I_{\mathrm{ds}} / I_{\mathrm{d} 00}(t)$ were measured at $V_{\mathrm{g}}=20 \mathrm{~V}$ and $V_{\mathrm{ds}}=0.2 \mathrm{~V}$. Normalized differential drainsource current was calculated as $\Delta I_{\mathrm{ds}} / I_{\mathrm{d} s 0}$, where $\Delta I_{\mathrm{ds}}$ is the difference between the signal obtained from working and control nanowires, and $I_{\mathrm{ds} 0}$ is the value of the signal before DNP addition. To improve time stability of SOI-NW sensors' operation, an additional Pt electrode was immersed into the solution in the measuring cell analogously [33, 34]. Differential signal was obtained by subtracting the nonspecific signal from that obtained upon addition of test DNP solution.

\section{Results and Discussion}

Time dependencies of normalized differential drain-source current signal $\Delta I_{\mathrm{ds}} / I_{\mathrm{d} 00}(t)$ were obtained for DNP concentrations from $3 \times 10^{-15} \mathrm{M}$ to $3 \times 10^{-13} \mathrm{M}$. Figure 3 displays typical time dependencies of the normalized differential signal from the SOI-NW sensor obtained upon DNP detection. Upon the addition of DNP into the measuring cell of the sensor system, an increase in the signal (due to the increase in nanowire conductivity caused by the influence of DNP) was observed (Figure 3). At that the signal value decreases with the decrease of DNP concentration. The lowest detectable DNP concentration was $3 \times 10^{-14} \mathrm{M}$.

Inset in Figure 3 displays typical $\Delta I_{\mathrm{ds}} / I_{\mathrm{ds} 0}(t)$ curves obtained in control experiments, when either DNP-free ethanol solution or pure deionized water was added into the measuring cell instead of DNP solution. These curves clearly indicate that upon addition of DNP-free test solution, the response from the sensor was either indistinguishable or exceeded the initial signal level insignificantly by no more than $2 \%$ (what is comparable with the noise level, which made up $\pm 5 \%$ ). This fact indicates specificity of interaction between silane layer on the sensor surface and DNP molecules.

To demonstrate the reproducibility of DNP detection, experiments on repeated detection of DNP with recording the signal from one and the same SOI-NW sensor have been carried out. Figure 4 displays typical $\Delta I_{\mathrm{ds}} / I_{\mathrm{ds} 0}(t)$ curves demonstrating the changes in the signal from one and the same SOI-NW upon repeated detection of DNP.

The curves displayed in Figure 4 indicate that upon repeated detection of DNP, the signal level changes by $\sim 15-20 \%$ with sufficient reproducibility.

Thus, SOI-NW sensors fabricated using CMOScompatible technology display the concentration limit of DNP detection at the level of $3 \times 10^{-14} \mathrm{M}$. This value is an order of magnitude lower than that demonstrated by Engel et al. [28] and comparable with the detection limit attained for TNT by Lichtenstein et al. [29]. Engel et al. [28] employed sensors fabricated using «bottom-up» technology without any special protective coating. As is known, SOINW sensors devoid of protective oxide coatings are lacking stability, what was demonstrated in a number of studies (including the study by Peled et al. [30] and our previous paper [18]). In the present study, we have employed SOINW sensors with protective layers of high- $k$ dielectrics. This has allowed us to obtain more stable and, at the same time, more sensitive structures [35]. The signal, observed upon the addition of DNP, is caused by the formation of complexes with a charge transfer between the DNP molecules and the amino groups of the silane layer; this leads to the change in surface potential of the silicon channel of the transistor [17]. 


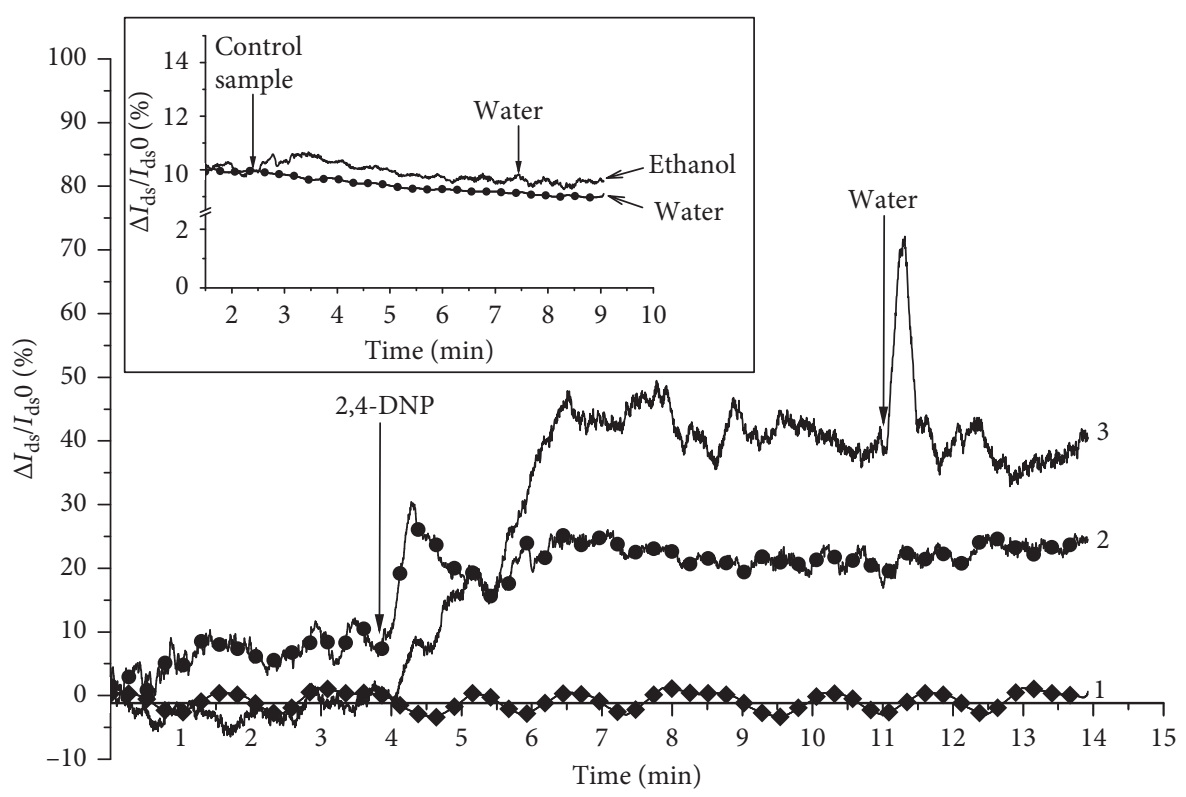

FIgURE 3: Time dependencies of the normalized differential signal from the SOI-NW sensor obtained upon DNP detection. DNP concentration $3 \times 10^{-15} \mathrm{M}$ (curve 1), $3 \times 10^{-14} \mathrm{M}$ (curve 2), and $3 \times 10^{-13} \mathrm{M}$ (curve 3) in deionized water. Inset displays examples of curves obtained in control experiments upon the addition of DNP-free solutions (ethanol or water) into the measuring cell. Experimental conditions: $V_{\mathrm{g}}=20 \mathrm{~V}$, $V_{\mathrm{ds}}=0.2 \mathrm{~V}$, and total solution volume in the cell $450 \mu \mathrm{L}$. Arrows indicate addition of DNP solution and washing with water.

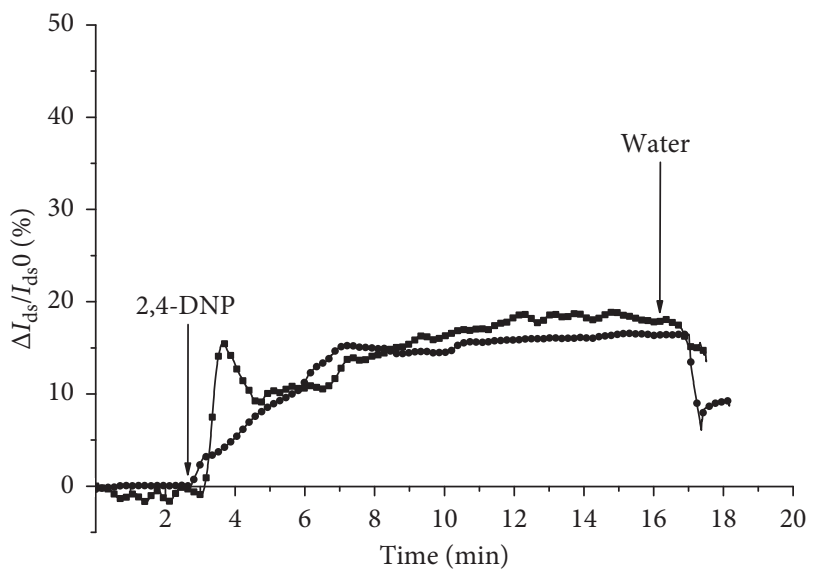

FIgURE 4: Time dependencies of the normalized differential signal from the SOI-NW sensor obtained upon repeated detection of DNP. Experimental conditions: DNP concentration $3.0 \times 10^{-14} \mathrm{M}$ in deionized water; $V_{\mathrm{g}}=20 \mathrm{~V}, V_{\mathrm{ds}}=0.2 \mathrm{~V}$ total solution volume in the cell $450 \mu \mathrm{L}$. Arrows indicate addition of DNP solution and wash with water.

It is worth noting that high stability of SOI-NW sensors with a protective layer has allowed us to reveal the desired signal against the background of a nonspecific signal from the ethanol-containing solution, which increases the transistor current (Figure 3, curve 2).

As was demonstrated by Engel et al., careful selection of surface modification can lead to an increase in sensor specificity and in sensitivity against nitrophenol analyte to be detected [28]. Therefore, in the future, to provide the specificity and to increase the sensitivity of DNP detection, various modifications of SOI-NW sensor surface can also be used. Accordingly, due to low price and manufacturability, the developed sensors based on lower-submicron CMOScompatible technology can well find application in highly sensitive detection of poisons and explosives. Moreover, these sensors can be arranged in multichannel arrays, from which separate sensitive units for detection of different target compounds can be formed.

\section{Conclusions}

Our study has demonstrated that SOI-NW sensors, fabricated using CMOS-compatible technology, allow direct highly sensitive detection of DNP with $3 \times 10^{-14} \mathrm{M}$ detection limit. These sensors can well be used for rapid monitoring of toxic compounds. SOI-NW sensors are cheap, easy to use, and can be adapted for detection of a wide range of toxic and explosive compounds by selection of sensor surface modification techniques.

\section{Data Availability}

The data underlying the results of this research can be provided on request directly to the interested person.

\section{Conflicts of Interest}

The authors declare that there are no conflicts of interest regarding the publication of this paper.

\section{Acknowledgments}

Ivan D. Shumov is a recipient of Russian Federation President Scholarship for Young Scientists for 2016-2018 (project identificator SP-4280.2016.4). This work was performed in the 
framework of the Program for Basic Research of State Academies of Sciences for 2013-2020.

\section{References}

[1] W. C. Cutting, H. G. Mehrtens, and M. L. Tainter, "Actions and uses of dinitrophenol: promising metabolic applications," Journal of the American Medical Association, vol. 101, no. 3, pp. 193-195, 1933.

[2] M. O. Harris and J. J. Cocoran, Toxicological Profile for Dinitrophenols, Agency for Toxic Substances and Disease Registry, Atlanta, GA, USA, 1995.

[3] J. Parascandola, "Dinitrophenol and bioenergetics: an historical perspective," Molecular and Cellular Biochemistry, vol. 5, no. 1-2, pp. 69-77, 1974.

[4] E. J. Miranda, I. M. McIntyre, D. R. Parker, R. D. Gary, and B. K. Logan, "Two deaths attributed to the use of 2,4-dinitrophenol," Journal of Analytical Toxicology, vol. 30, no. 3, pp. 219-222, 2006.

[5] E. Colman, "Dinitrophenol and obesity: an early twentiethcentury regulatory dilemma," Regulatory Toxicology and Pharmacology, vol. 48, no. 2, pp. 115-117, 2007.

[6] Y. Q. Lu, J. K. Jiang, and W. D. Huang, "Clinical features and treatment in patients with acute 2,4-dinitrophenol poisoning," Journal of Zhejiang University Science B, vol. 12, no. 3, pp. 189-192, 2011.

[7] J. Grundlingh, P. I. Dargan, M. El-Zanfaly, and D. M. Wood, "2,4-Dinitrophenol (DNP): a weight loss agent with significant acute toxicity and risk of death," Journal of Medical Toxicology, vol. 7, no. 3, pp. 205-212, 2011.

[8] J. C. Geiger, "A death from alpha-dinitrophenol poisoning," Journal of the American Medical Association, vol. 101, no. 17, p. 1333, 1933.

[9] A. Tewari, A. Ali, A. O'Donnell, and M. S. Butt, "Weight loss and 2,4-dinitrophenol poisoning," British Journal of Anaesthesia, vol. 102, no. 4, pp. 566-567, 2009.

[10] R. B. McFee, T. R. Caraccio, M. A. McGuigan, S. A. Reynolds, and P. Bellanger, "Dying to be thin: a dinitrophenol related fatality," Veterinary and Human Toxicology, vol. 46, no. 5, pp. 251-254, 2004.

[11] R. B. Leftwich, J. F. Floro, R. A. Neal, and A. J. Wood, "Dinitrophenol poisoning: a diagnosis to consider in undiagnosed fever," Southern Medical Journal, vol. 75, no. 2, pp. 182-184, 1982.

[12] A. L. Hsiao, K. A. Santucci, P. Seo-Mayer et al., "Pediatric fatality following ingestion of dinitrophenol: postmortem identification of a "dietary supplement"," Clinical Toxicology, vol. 43, no. 4, pp. 281-285, 2005.

[13] D. N. Baterman and A. Vale, "Paracetamol (aminophen)," Medicine, vol. 44, no. 3, pp. 190-192, 2016.

[14] G. Maduraiveeran, R. Rasik, M. Sasidharan, and W. Jin, "Bimetallic gold-nickel nanoparticles as a sensitive amperometric sensing platform for acetaminophen in human serum," Journal of Electroanalytical Chemistry, vol. 808, pp. 259-265, 2018.

[15] T. Urbanski, Chemistry and Technology of Explosives, Pergamon Press, Vol. 1, Pergamon Press, Oxford, UK, 1964.

[16] T. O. Pleshakova, I. D. Shumov, Y. D. Ivanov, K. A. Malsagova, A. L. Kaysheva, and A. I. Archakov, "AFM-based technologies as the way towards the reverse Avogadro number," Biochemistry (Moscow) Supplement Series B: Biomedical Chemistry, vol. 9, no. 3, pp. 244-257, 2015.

[17] Y. D. Ivanov, T. O. Pleshakova, A. F. Kozlov et al., "SOI nanowire for the high-sensitive detection of HBsAg and a-fetoprotein," Lab on a Chip, vol. 12, no. 23, pp. 5104-5111, 2012.

[18] K. A. Malsagova, Y. D. Ivanov, T. O. Pleshakova et al., "A SOInanowire biosensor for the multiple detection of D-NFATc1 protein in the serum," Analytical Methods, vol. 7, no. 19, pp. 8078-8085, 2015.

[19] X. P. Gao, G. Zheng, and C. M. Lieber, "Subthreshold regime has the optimal sensitivity for nanowire FET biosensors," Nano Letters, vol. 10, no. 2, pp. 547-552, 2010.

[20] Y. D. Ivanov, T. O. Pleshakova, K. A. Malsagova et al., "Detection of marker miRNAs in plasma using SOI-NW biosensor," Sensors and Actuators B: Chemical, vol. 261, pp. 566-571, 2018.

[21] M. K. Nakhleh, H. Amal, R. Jeries et al., "Diagnosis and classification of 17 diseases from 1404 subjects via pattern analysis of exhaled molecules," ACS Nano, vol. 11, no. 1, pp. 112-125, 2017.

[22] G. Maduraiveeran, M. Sasidharan, and V. Ganesan, "Electrochemical sensor and biosensor platforms based on advanced nanomaterials for biological and biomedical applications," Biosensors and Bioelectronics, vol. 103, pp. 113-129, 2018.

[23] G. Maduraiveeran and W. Jin, "Nanomaterials based electrochemical sensor and biosensor platforms for environmental applications," Trends in Environmental Analytical Chemistry, vol. 13, pp. 10-23, 2017.

[24] O. V. Naumova, B. I. Fomin, D. A. Nasimov et al., "SOI nanowires as sensors for charge detection," Semiconductor Science and Technology, vol. 25, no. 5, article 055004, 2010.

[25] L. Luo, J. Jie, W. Zhang et al., "Silicon nanowire sensors for $\mathrm{Hg}$ $2+$ and Cd $2+$ ions," Applied Physics Letters, vol. 94, no. 19, article 193101, 2009.

[26] A. Cao, E. Sudhölter, and L. de Smet, "Silicon nanowire: based devices for gas-phase sensing," Sensors, vol. 14, no. 1, pp. 245-271, 2014.

[27] A. A. Talin, L. L. Hunter, F. Léonard, and B. Rokad, "Large area, dense silicon nanowire array chemical sensors," Applied Physics Letters, vol. 89, no. 15, article 153102, 2006.

[28] Y. Engel, R. Elnathan, A. Pevzner, G. Davidi, E. Flaxer, and F. Patolsky, "Supersensitive detection of explosives by silicon nanowire arrays," Angewandte Chemie International Edition, vol. 49, no. 38, pp. 6830-6835, 2010.

[29] A. Lichtenstein, E. Havivi, R. Shacham et al., "Supersensitive fingerprinting of explosives by chemically modified nanosensors arrays: "facing explosives"," Nature Communications, vol. 5, no. 1, 2014.

[30] A. Peled, A. Pevzner, H. P. Soroka, and F. Patolsky, "Morphological and chemical stability of silicon nanostructures and their molecular overlayers under physiological conditions: towards long-term implantable nanoelectronic biosensors," Journal of Nanobiotechnology, vol. 12, no. 1, p. 7, 2014.

[31] N. Shehada, J. C. Cancilla, J. S. Torrecilla et al., "Silicon nanowire sensors enable diagnosis of patients via exhaled breath," ACS Nano, vol. 10, no. 7, pp. 7047-7057, 2016.

[32] T. O. Pleshakova, A. L. Kaysheva, J. M. Bayzyanova et al., "Advantages of aptamers as ligands upon protein detection by AFM-based fishing," Analytical Methods, vol. 9, no. 42, pp. 6049-6060, 2017.

[33] R. Tian, S. Regonda, J. Gao, Y. Liu, and W. Hu, "Ultrasensitive protein detection using lithographically defined Si multinanowire field effect transistors," Lab on a Chip, vol. 11, no. 11, pp. 1952-1961, 2011. 
[34] K. A. Malsagova, Y. D. Ivanov, T. O. Pleshakova et al., "SOInanowire biosensor for detection of D-NFATc1 protein," Biochemistry (Moscow) Supplement Series B: Biomedical Chemistry, vol. 8, no. 3, pp. 220-225, 2014.

[35] V. P. Popov, M. A. Ilnitskii, E. D. Zhanaev, A. V. Myakon'kich, K. V. Rudenko, and A. V. Glukhov, "Biosensor properties of SOI nanowire transistors with PEALD Al2O3 dielectric protective layer," Semiconductors, vol. 50, no. 5, pp. 632-638, 2016. 


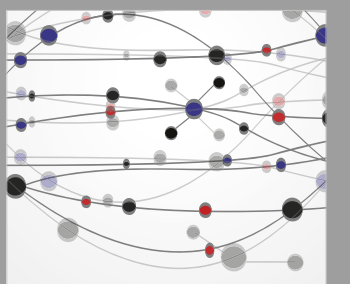

The Scientific World Journal
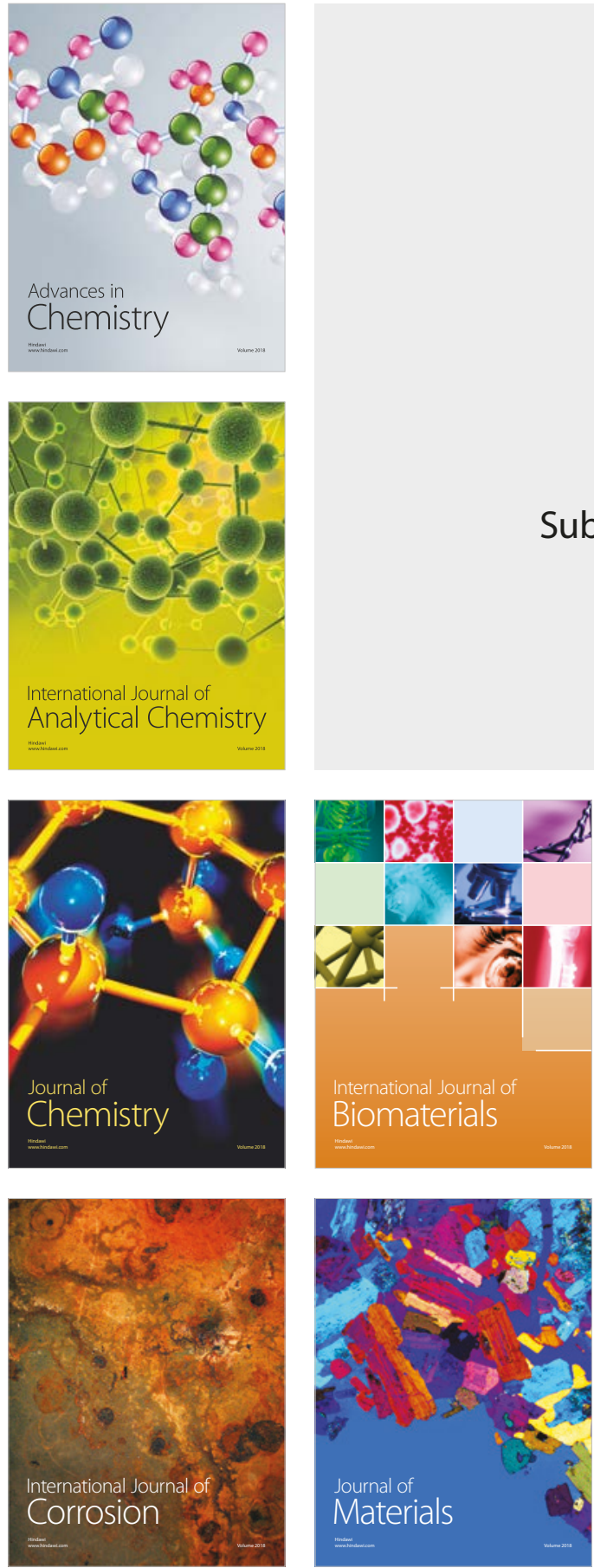

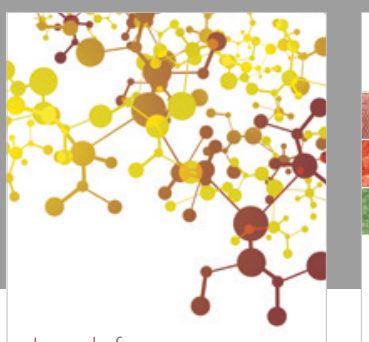

Journal of

Applied Chemistry
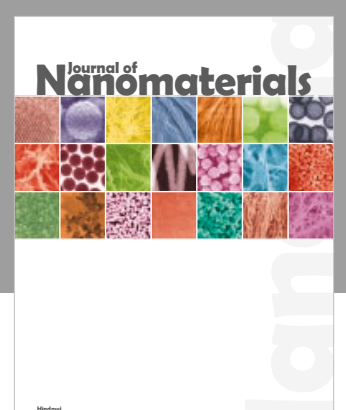

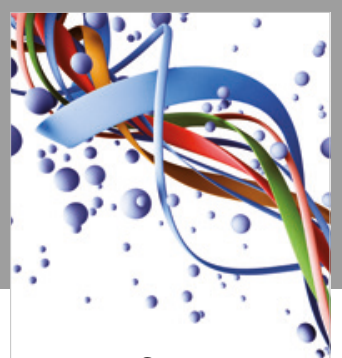

Scientifica

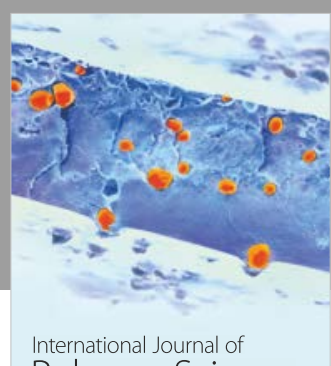

Polymer Science

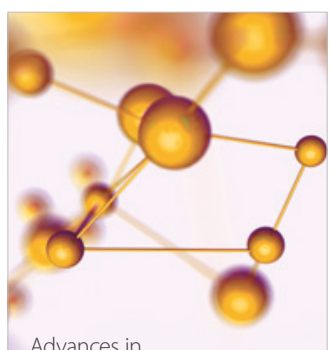

Physical Chemistry
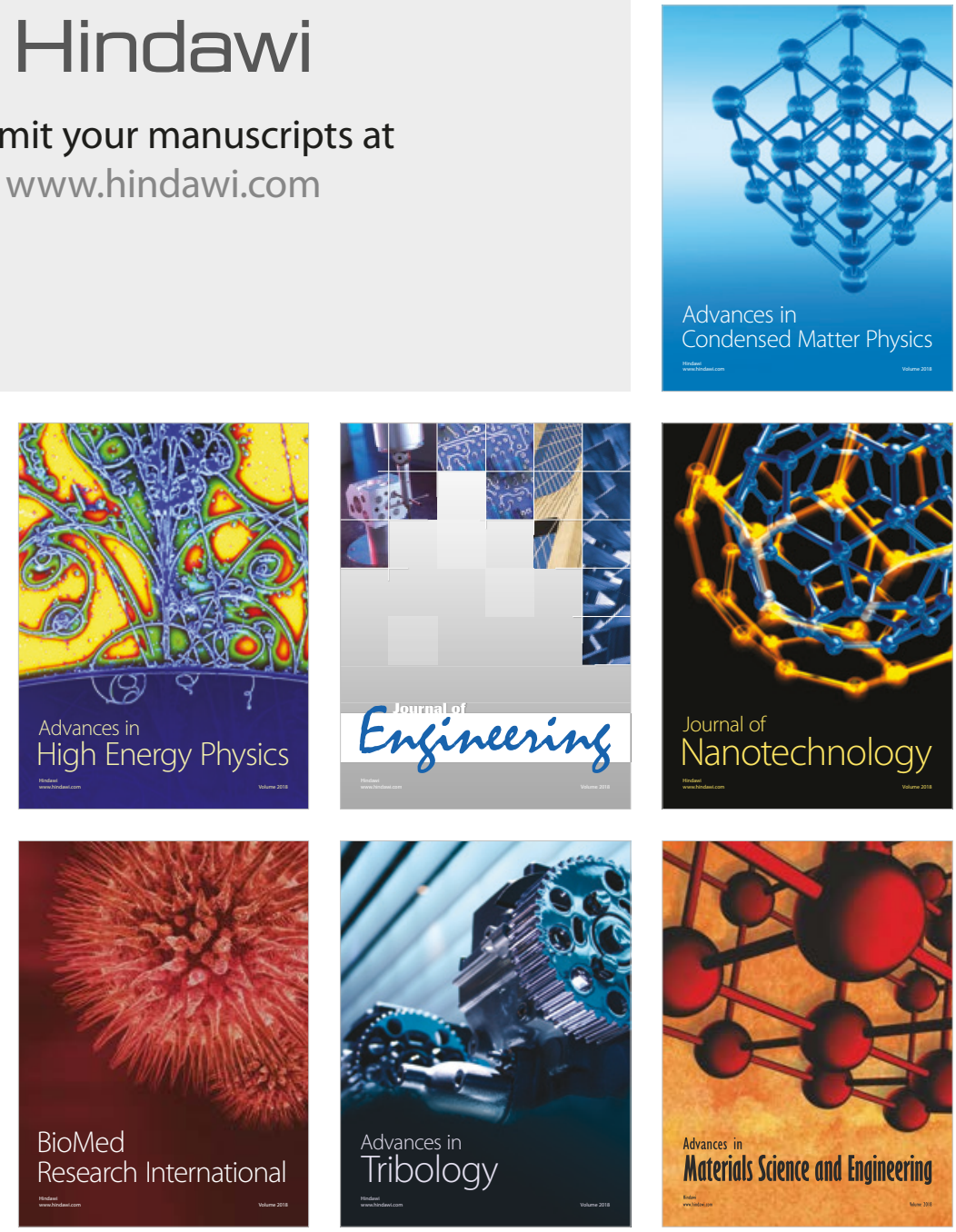